\title{
Glaucoma medication non-compliance in Hebron, Palestine
}

\author{
Riyad G. Banayot $\odot$ \\ St John Eye Hospital, Hebron, Palestine
}

\begin{abstract}
BACKGROUND: The purpose of this study was to determine patient characteristics, estimate the extent of compliance of glaucoma patients with medication, the technique of drop instillation, and follow-up clinic visits.

MATERIAL AND METHODS: We interviewed all glaucoma patients attending their regular follow-up visits, over three months, at St. John Eye Hospital, Hebron, Palestine. A questionnaire with 34 questions was used to fill patient responses. The questions dealt with patient characteristics: glaucoma treatments, and their awareness and attitudes towards different components of non-compliance with medical treatment. We also observed the patient's practice of instilling placebo eye drops.

RESULTS: We interviewed 44 patients: 33 females (75\%) and 11 males (25\%). Patients using more than one drop constituted $63 \%$ of patients. $82 \%$ of patients affirmed "Not missing doses last week", and 52\% stated that they "Never stopped taking drops in the past", while only $36 \%$ of files showed drop compliance. $91 \%$ of patients claimed to make follow-up visits on time, while documented follow-up compliance was $64 \%$.

CONCLUSION: This study revealed a poor agreement between subjective compliance and file records among Palestinian patients with glaucoma visiting our clinic. We need to educate our glaucoma patients about the disease and its complications, drop administration technique, compliance with drop administration, and clinic visits.
\end{abstract}

KEY WORDS: glaucoma; non-compliance; medication compliance; follow-up visit compliance; Hebron

Ophthalmol J 2021; Vol. 6, 10-16

\section{INTRODUCTION}

Glaucoma is a slowly progressive and initially asymptomatic disease characterized by optic nerve atrophy and visual field loss. Glaucoma is the leading cause of worldwide irreversible blindness $[1,2]$. Glaucoma presents many challenges to long-term patient compliance with therapy.

Glaucoma patients need continuing treatment after disease detection. Therefore, compliance with medical treatment is a significant concern. Reported compliance rates from glaucoma studies have differed widely from five to $80 \%$ [3].

Medical management of glaucoma depends primarily on the administration of topical ocu- lar medications. Non-compliance with prescribed treatments has proven to be a significant problem for effective glaucoma management. Kass et al. [4] found that most patients overestimate their compliance and that physicians cannot determine which patients adhere to the prescribed therapy.

Another obstacle in the medical treatment of glaucoma is the improper administration of ocular drops by patients. Inadequate data on the prevalence of improper administration techniques exist, but it may be as high as $80 \%[5,6]$.

The outcomes of this study are to estimate compliance with medication, compliance with the technique of drop instillation, and follow-up visit compliance. 


\section{MATERIAL AND METHODS}

We performed a descriptive study of all glaucoma patients attending their regular follow-up visit at St. John Eye Hospital, Hebron, for three months. The researcher interviewed patients who agreed to be included in the study post their regular clinic visit. The researcher explained the purpose of the study to each patient and used a questionnaire to collect patient responses. The questionnaire and scoring system were composed by the researcher and were never validated by previous studies. The questionnaire had 34 questions grouped into four sections illustrated in Figure 1. The first section dealt with the patient's characteristics, features of their disease, and the number of drops used. The second section dealt with the patient's knowledge and attitude. The third section dealt with treatment compliance. For each question in the second and third sections, the researcher explained the multiple answers, and the patient's answers were recorded. The fourth section dealt with the drop administration technique. First, the researcher asked the questions, answers were noted, and then the researcher witnessed how the patient instilled artificial teardrops.

The overall score of the knowledge and attitude questions (second section) was calculated by summing the positive responses ("Yes"; "Yes, always"; "Always"). We divided patients' scores into four groups: "Excellent knowledge" (> 75\%), "Good knowledge" (50-75\%), "Poor knowledge" (25-50\%), and "Very poor knowledge" $(<25 \%)$. The overall score of the compliance questions (third section) was calculated by summing the positive responses ("Never missed"; "Seen at least every six months"; "Yes"; "No"). We divided patients' scores into four groups: "Excellent compliance" (> 75\%), "Good compliance" (50-75\%), "Poor compliance" (25-50\%), and "Very poor compliance" $(<25 \%)$. The overall score of the technique questions (fourth section) was calculated by summing the positive responses ("Yes, always"; "Yes"). We divided patients' scores into four groups: "Excellent technique" (> 75\%), "Good technique" (50-75\%), "Poor technique" (25-50\%), and "Very poor technique" $(<25 \%)$. Drop administration, and contamination scores were calculated by summing observations of positive technique (drops "on target"; "no contamination"). The researcher obtained verbal consent for participation in the study from all patients. The identity of patients was concealed to maintain confidentiality.

We defined non-compliance in this study as missing at least one drop per week and/or irregularity of doctor visits (lapse between visits > six months).

\section{RESULTS}

Patient characteristics of 44 patients reviewed in our study are presented in Table 1 . The majority of our patients were female and homemakers, who had glaucoma for less than five years, had medical insurance and paid 14-86 USD out-of-pocket/month for drops, were illiterate, or had primary schooling.

We compared the knowledge, compliance, and technique among our patients according to the results of their scores (Tab. 2). Knowledge was excellent in most categories, but poor knowledge was seen when patients were asked to rate glaucoma severity and when asked about awareness of risks of missing glaucoma drops. We graded overall knowledge as good, with $60 \%$ of patients responding positively to the knowledge questions.

Compliance with drops was excellent in most categories, with $82 \%$ of patients reporting using their drops the previous week. Clinic visit follow-up compliance was $91 \%$. We graded overall medication compliance as excellent, with $79 \%$ of patients responding positively to the compliance questions. We found excellent compliance in $76-87 \%$ for different patient categories (Tab. 3).

We found that $80 \%$ of patients showed excellent "drop administration technique". We observed tip contamination in 59\% of cases, although 55\% of patients responded otherwise in the questionnaire. Patients showed very poor results for "closing punctum after applying drops" and for "Waiting for three or more minutes between drops". We graded the overall technique as a poor technique.

\section{DISCUSSION}

Non-compliance is a multifaceted challenge in chronic silent diseases such as glaucoma, where patients are not familiar with the effect of non-compliance for a long time. To make matters worse, newer drugs, disagreements between ophthalmologists about the most effective medication, and their high costs pose a problem for patients with glaucoma, which could lead to non-compliance.

We observed in our study that the overall compliance to be $79 \%$ and follow-up compliance was 91\% (40/44 files). We should interpret these results cautiously because of the contradicting information extracted from patients' files where 16 files (16/44) showed more than six-month lapses between visits, which decrease compliance from $91 \%$ to $64 \%$. Similarly, 23 patients replied that they never stopped 


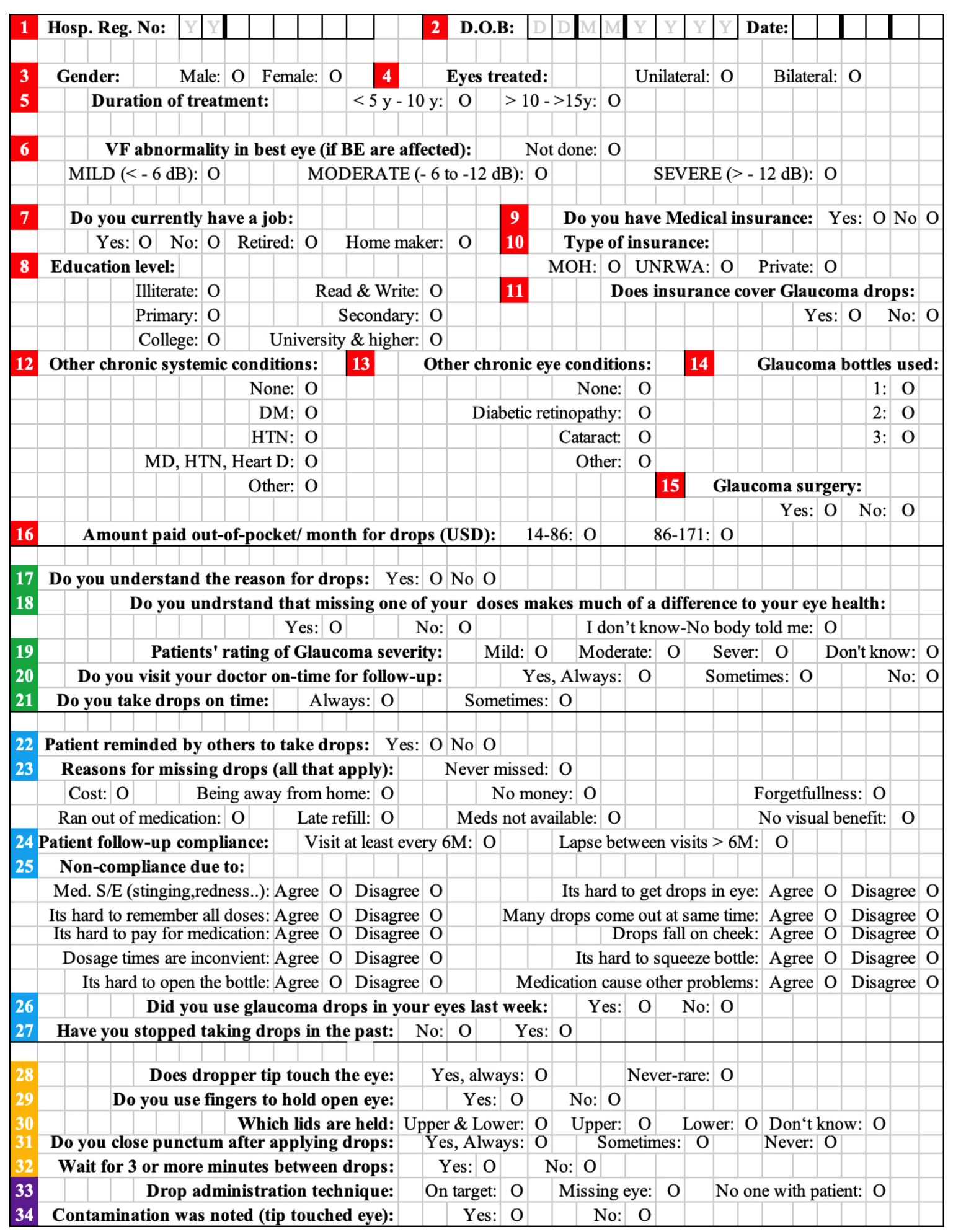

FIGURE 1. The questionnaire and scoring system

drops in the past while there was evidence in their files showing that in seven cases (seven files out of 23), either the patient ran out of medication or it was noted that they stopped drops on their own, which decreases compliance in this category from $52 \%$ to $36 \%$. 


\begin{tabular}{|c|c|c|c|c|c|}
\hline Category & No & $\%$ & Category & No & $\%$ \\
\hline \multicolumn{3}{|l|}{ Age group } & \multicolumn{3}{|l|}{ Visual field abnormality in best eye } \\
\hline$<50-69$ years & 25 & $57 \%$ & Mild $(<-6 \mathrm{~dB})$ & 13 & $30 \%$ \\
\hline $70-\geq 80$ Years & 19 & $43 \%$ & Moderate $(-6$ to $-12 \mathrm{~dB})$ & 4 & $9 \%$ \\
\hline \multicolumn{3}{|l|}{ Gender } & Severe $(>-12 \mathrm{~dB})$ & 12 & $27 \%$ \\
\hline Female & 33 & $75 \%$ & Not done & 15 & $34 \%$ \\
\hline Male & 11 & $25 \%$ & \multicolumn{3}{|l|}{ Glaucoma surgery } \\
\hline \multicolumn{3}{|l|}{ Medical insurance } & Yes & 9 & $20 \%$ \\
\hline Yes & 40 & $91 \%$ & No & 35 & $80 \%$ \\
\hline Ministry of Health & 32 & $73 \%$ & \multicolumn{3}{|l|}{ Eyes treated } \\
\hline United Nations Relief Works Agency (UNRWA) & 8 & $18 \%$ & Bilateral & 28 & $64 \%$ \\
\hline No & 4 & $9 \%$ & Unilateral & 16 & $36 \%$ \\
\hline \multicolumn{3}{|l|}{ Does insurance cover glaucoma drops? } & \multicolumn{3}{|l|}{ Other chronic eye conditions } \\
\hline Yes & 1 & $2 \%$ & None & 22 & $50 \%$ \\
\hline No & 39 & $89 \%$ & Diabetic retinopathy & 2 & $5 \%$ \\
\hline \multicolumn{3}{|l|}{ Educational level } & Cataract & 8 & $18 \%$ \\
\hline Illiterate — Primary & 31 & $70 \%$ & Other & 12 & $27 \%$ \\
\hline Secondary — University & 13 & $30 \%$ & \multicolumn{3}{|l|}{ Other chronic systemic conditions } \\
\hline \multicolumn{3}{|l|}{ Amount paid/month for drops [USD] } & None & 16 & $36 \%$ \\
\hline $14-86$ & 41 & $93 \%$ & Diabetes, hypertension, heart disease & 10 & $23 \%$ \\
\hline $86-171$ & 3 & $7 \%$ & Diabetes & 3 & $7 \%$ \\
\hline \multicolumn{3}{|l|}{ Occupation } & Hypertension & 8 & $18 \%$ \\
\hline Yes & 6 & $14 \%$ & Other & 7 & $16 \%$ \\
\hline No & 2 & $5 \%$ & \multicolumn{3}{|l|}{ Number of glaucoma bottles used } \\
\hline Retired & 7 & $16 \%$ & 1 & 16 & $36 \%$ \\
\hline Home maker & 29 & $66 \%$ & 2 & 23 & $52 \%$ \\
\hline \multicolumn{3}{|l|}{ Duration of treatment } & 3 & 5 & $11 \%$ \\
\hline$<5-10$ years & 36 & $82 \%$ & & & \\
\hline$>10->15$ years & 8 & $18 \%$ & & & \\
\hline
\end{tabular}

Masoud et al. [7] found compliance with medication prescriptions for glaucoma about 50\% among the Arab population in Israel. In other studies, non-compliance among glaucoma patients varied; $38 \%$ by Spooner et al. [8], 24.7\% by Gurwitz et al. [9], $75.2 \%$ by Khandekar et al. [10]. In a survey of glaucoma patients in Canada [11], 27.9\% were found non-compliant with their eye drop administration, and about a third demonstrated improper administration technique. The explanations for this wide variation could be due to different definitions, different levels of education, different methods of payment for medications, and different patterns of behavior between patients in different countries.

In our study, compliance was slightly higher in males $[82 \%(9 / 11)]$ than females $[79 \%(26 / 33)]$. Djafari et al. [12] and Khandekar et al. found no significant relationship between non-compliance and gender. Bloch [13] reported higher non-compliance rates in males than females, but Aziz et al. [14] reported worse non-compliance among females than males. In the same report, Aziz et al. identified that non-compliance was highest in the elderly. In our study, there were no significant differences in non-compliance between the different age groups. Support for elderly people by other family members in Palestinian society may have resulted in better compliance among elderly patients.

Khandekar et al. reported that glaucoma patients had very high compliance rates for regular follow-up visits and judiciously adhered to dosage frequencies. Our study showed the same results.

Overall knowledge of glaucoma was good in $60 \%$ of patients. Khandekar et al. reported $23.8 \%$ 
Table 2. Knowledge, compliance, and technique scores

\begin{tabular}{|c|c|c|c|c|c|c|}
\hline & \multicolumn{2}{|c|}{ Excellent } & \multicolumn{2}{|c|}{ Good } & \multicolumn{2}{|c|}{ Poor } \\
\hline Knowledge & No. & $\%$ & No. & $\%$ & No. & $\%$ \\
\hline Do you understand the reason for drops? & 28 & $64 \%$ & & & 16 & $36 \%$ \\
\hline $\begin{array}{l}\text { Do you understand that missing out one of your drop doses makes much of } \\
\text { a difference to your eye health? }\end{array}$ & 14 & $32 \%$ & & & 30 & $68 \%$ \\
\hline Patients' rating of glaucoma severity & 12 & $27 \%$ & & & 32 & $73 \%$ \\
\hline Do you visit your doctor on-time for follow-up? & 35 & $80 \%$ & 6 & $14 \%$ & 3 & $7 \%$ \\
\hline Do you take drops on time? & 43 & $98 \%$ & 1 & $2 \%$ & & \\
\hline \multirow[t]{2}{*}{ Overall knowledge } & & $60 \%$ & & & & \\
\hline & \multicolumn{2}{|c|}{ Excellent } & \multicolumn{2}{|c|}{ Good } & \multicolumn{2}{|c|}{ Very poor } \\
\hline Compliance & No. & $\%$ & No. & $\%$ & No. & $\%$ \\
\hline Reminded by others to use drops & 40 & $91 \%$ & & & 4 & $9 \%$ \\
\hline Follow-up compliance & 40 & $91 \%$ & & & 4 & $9 \%$ \\
\hline Used drops last week & 36 & $82 \%$ & & & 8 & $18 \%$ \\
\hline Have you stopped taking drops in the past? & 23 & $52 \%$ & & & 21 & $48 \%$ \\
\hline \multirow[t]{2}{*}{ Overall Compliance } & & $79 \%$ & & & & \\
\hline & \multicolumn{2}{|c|}{ Excellent } & \multicolumn{2}{|c|}{ Poor } & \multicolumn{2}{|c|}{ Very Poor } \\
\hline Technique & No. & $\%$ & No. & $\%$ & No. & $\%$ \\
\hline Does tip of dropper touch the eye? & 24 & $55 \%$ & 4 & $9 \%$ & 16 & $36 \%$ \\
\hline Do you use fingers to hold an open eye? & 37 & $84 \%$ & & & 7 & $16 \%$ \\
\hline Do you close punctum after applying drops? & 4 & $9 \%$ & 1 & $2 \%$ & 39 & $89 \%$ \\
\hline Wait for 3 or more minutes between drops & 9 & $20 \%$ & & & 35 & $80 \%$ \\
\hline Observed: Drop administration technique (№. $=41$ ) & 33 & $80 \%$ & & & 8 & $20 \%$ \\
\hline Observed: Contamination (tip touched eye) $($ No. $=41$ ) & 15 & $37 \%$ & & & 26 & $59 \%$ \\
\hline Overall Technique & & $42 \%$ & & & & \\
\hline Observed technique and contamination & & $59 \%$ & & & & \\
\hline
\end{tabular}

\section{Table 3. Compliance for different categories}

\begin{tabular}{|c|c|c|c|c|}
\hline & \multicolumn{2}{|c|}{ Compliant } & \multicolumn{2}{|c|}{ Non-compliant } \\
\hline & No. & $\%$ & No. & $\%$ \\
\hline \multicolumn{5}{|l|}{ Gender } \\
\hline Female $(n=33)$ & 26 & $79.0 \%$ & 7 & $21.0 \%$ \\
\hline Male $(n=11)$ & 9 & $82.0 \%$ & 2 & $18.0 \%$ \\
\hline \multicolumn{5}{|l|}{ Age group } \\
\hline$<50-69$ y $(n=25)$ & 19 & $76.0 \%$ & 6 & $24.0 \%$ \\
\hline $70-\geq 80$ y $(n=19)$ & 16 & $84.0 \%$ & 3 & $16.0 \%$ \\
\hline \multicolumn{5}{|l|}{ Educational level } \\
\hline Illiterate — Primary $(\mathrm{n}=31)$ & 25 & $81.0 \%$ & 6 & $19.0 \%$ \\
\hline Secondary - University $(n=.13)$ & 11 & $85.0 \%$ & 2 & $15.0 \%$ \\
\hline \multicolumn{5}{|l|}{ Duration of treatment } \\
\hline$<5-10$ y $(n=36)$ & 28 & $78.0 \%$ & 8 & $22.0 \%$ \\
\hline$>10->15$ y $(n=8)$ & 7 & $87.0 \%$ & 1 & $13.0 \%$ \\
\hline
\end{tabular}


on knowledge of glaucoma, and Lau et al. [15] reported $10.2 \%$ on knowledge of glaucoma symptoms. While 43 patients replied that they took drops on time, logs in 21 files showed notes such as "non-compliant with drops".

Patel and Spaeth [16] found that the main reasons provided by patients for non-compliance included forgetfulness (39\%), while Taylor et al. [17] also reported that patient forgetfulness was the number-one reason for non-compliance. In our study, $50 \%$ of non-compliant patients reported "ran out of medication".

Overall observed technique and contamination were 59\% and graded as good. Out of 41 patients, four missed the eye, and four did not know how to instill the drops, while in 26 patients contamination of dropper tips was observed.

The study has several limitations. First, the measure of compliance was subjective. Second, glaucoma patients attending Ministry of Health $(\mathrm{MOH})$, United Nations Relief Works Agency (UNRWA), and other private clinics were not represented in our study (their characteristics could differ from our study). Third, the small number of patients in our research and the small number of male patients (these could be attributed to the study design) made multivariate and subgroup analysis not feasible. Fourth, because the researcher conducted the study (based on patients' responses), we cannot rule out social desirability bias. Therefore, we should interpret our results with caution regarding glaucoma patients in Palestine.

Information on non-compliance components is also important in formulating the policies to improve awareness and counseling of patients with glaucoma while prescribing medications.

Improving compliance with glaucoma medication regimens is critical, and future research in this area is required. Patient compliance is essential for effective medication intervention and to reduce the peripheral and central loss of vision.

\section{CONCLUSION}

This study revealed a poor agreement between subjective compliance and file records for Palestinian patients with glaucoma. This demands larger studies to confirm the results and reveal relevant issues in improving patients' compliance. We need to teach our glaucoma patients about the disease and its complications. We also must make sure the patients know how to instill their drops, and last, we must teach patients about the importance of compliance with drop administration and clinic visits. [18] Recommended plans to improve compliance may include: Improve patient-physician communication, education, and motivation through leaflets, use of smart technology (smartphones as a reminder), rethinking of new drug delivery systems, early laser or surgical interventions [19].

\section{Acknowledgments \\ NIL.}

\section{Conflict of interest}

NIL.

\section{REFERENCES}

1. Kingman $\mathrm{S}$. Glaucoma is second leading cause of blindness globally. Bull World Health Organ. 2004; 82(11): 887-888, doi: /SO04296862004001100019, indexed in Pubmed: 15640929.

2. Quigley HA, Broman AT. The number of people with glaucoma worldwide in 2010 and 2020. Br J Ophthalmol. 2006; 90(3): 262-267, doi: 10.1136/bjo.2005.081224, indexed in Pubmed: 16488940.

3. Olthoff C, Schouten J, van de Borne B, et al. Noncompliance with Ocular Hypotensive Treatment in Patients with Glaucoma or Ocular HypertensionAn Evidence-Based Review. Ophthalmology. 2005; 112(6): 953-961.e7, doi: 10.1016/j.ophtha.2004.12.035.

4. Kass MA, Meltzer DW, Gordon M, et al. Compliance with topical pilocarpine treatment. Am J Ophthalmol. 1986; 101(5): 515523, doi: 10.1016/0002-9394(86)90939-6, indexed in Pubmed: 3706455 .

5. Brown MM, Brown GC, Spaeth GL. Improper topical self-administration of ocular medication among patients with glaucoma. Can J Ophthalmol. 1984; 19(1): 2-5, indexed in Pubmed: 6608974.

6. Konstas AG, Maskaleris G, Gratsonidis S, et al. Compliance and viewpoint of glaucoma patients in Greece. Eye (Lond). 2000; $14 \mathrm{Pt} 5$ : 752-756, doi: 10.1038/eye.2000.197, indexed in Pubmed: 11116698.

7. Masoud M, Sharabi-Nov A, Pikkel J. Noncompliance with Ocular Hypertensive Treatment in Patients with Primary Open Angle Glaucoma among the Arab Population in Israel: A Cross-Sectional Descriptive Study. J Ophthalmol. 2013; 2013: 405130, doi: 10.1155/2013/405130, indexed in Pubmed: 23936632.

8. Spooner JJ, Bullano MF, Ikeda LI, et al. Rates of discontinuation and change of glaucoma therapy in a managed care setting. AmJ Manag Care. 2002; 8(10 ): Suppl-S262, doi: S270, indexed in Pubmed: 12188169.

9. Gurwitz JH, Yeomans SM, Glynn RJ, et al. Patient noncompliance in the managed care setting. The case of medical therapy for glaucoma. Med Care. 1998; 36(3): 357-369, doi: 10.1097/00005650-19980300000012, indexed in Pubmed: 9520960.

10. Khandekar R, Shama MES, Mohammed AJ. Noncompliance with medical treatment among glaucoma patients in 0man - a cross-sectional descriptive study. Ophthalmic Epidemiol. 2005; 12(5): 303-309, doi: 10.1080/09286580500224602, indexed in Pubmed:16272050.

11. Kholdebarin R, Campbell RJ, Jin YP, et al. Multicenter study of compliance and drop administration in glaucoma. Can J Ophthalmol. 2008; 43(4): 454-461, doi: 10.1139/i08-076, indexed in Pubmed: 18711461

12. Djafari F, Lesk MR, Harasymowycz PJ, et al. Determinants of adherence to glaucoma medical therapy in a long-term patient population. J Glaucoma. 2009; 18(3): 238-243, doi: 10.1097/IJG.0b013e3181815421, indexed in Pubmed: 19295380.

13. Bloch $S$, Rosenthal $A R$, Friedman $L$, et al. Patient compliance in glaucoma. Br J Ophthalmol. 1977; 61(8): 531-534, doi: 10.1136/ bjo.61.8.531, indexed in Pubmed: 911733. 
14. Aziz AM, lbrahim MI. Medication noncompliance - a thriving problem. Med J Malaysia. 1999; 54(2): 192-199, indexed in Pubmed: 10972029.

15. Lau JTF, Lee V, Fan D, et al. Knowledge about cataract, glaucoma, and age related macular degeneration in the Hong Kong Chinese population. Br J Ophthalmol. 2002; 86(10): 1080-1084, doi: 10.1136/ bjo.86.10.1080, indexed in Pubmed: 12234882.

16. Patel SC, Spaeth GL. Compliance in patients prescribed eyedrops for glaucoma. Ophthalmic Surg. 1995; 26(3): 233-236, indexed in Pubmed: 7651690.
17. Taylor SA, Galbraith SM, Mills RP. Causes of non-compliance with drug regimens in glaucoma patients: a qualitative study. J Ocul Pharmacol Ther. 2002; 18(5): 401-409, doi: 10.1089/10807680260362687, indexed in Pubmed: 12419091.

18. AAO PPP. AAO PPP. Summary benchmarks for preferred practice pattern $\AA$ guidelines. Oct 2018. Glaucoma Summary Benchmarks 2018.

19. Lori Baker-Schena. Patient adherence. AAO EyeNet Mag 2017; 51-55. https://www.aao.org/eyenet/article/patient-adherence. 